\author{
Department of Internal Medicine \\ Division of Endocrinology and Metabolism and The Metabolism Research Unit \\ Department of Biological Chemistry \\ University of Michigan, Ann Arbor
}

\title{
INSULIN AND GLUCAGON SECRETION IN ESSENTIAL FATTY ACID DEFICIENT RATS
}

\author{
Jones O. Akpan Mary C. Hurley William E. M. Lands
}

Essential fatty acids (EFA) are those fatty acids which animals cannot synthesize in amounts adequate for proper growth, maintenance and functioning of many physiological processes ${ }^{1}$. There are two common essential fatty acids, linoleic acid [9,12-octadecadienic acid; 18:2(n-6)] and arachidonic acid [5,8,11,14-eicosatetraenoic acid; $20: 4(\mathrm{n}-6)$ ], which adequately alleviate the symptoms of EFA deficiency in pathologic or experimentally induced conditions ${ }^{1}$. Linoleic acid is a precursor of arachidonic acid and is converted to the latter by $\Delta 6$ desaturation of linoleic acid to- $\gamma$-linolenic acid $[18: 3(n-6)]$ followed by chain elongation to dihomo- $\gamma$-linolenic acid $[20: 3(\mathrm{n}-6)]$ and then by $\Delta 5$ desaturation to arachidonic acid ${ }^{3}$. Arachidonic acid is a precursor of the dienoic series of prostaglandins such as prostaglandin (PG) $\mathrm{H}_{2}, \mathrm{E}_{2}, \mathrm{~F}_{2}, \mathrm{D}_{2}, \mathrm{I}_{2}$ (prostacyclin), and thromboxane $\mathrm{A}_{2}$. The monoene series of prostaglandins, such as $\mathrm{PGE}_{1}$, is derived from dihomo- $\gamma$-linolenic acid ${ }^{3,36}$.

Tissues from essential fatty acid deficient animals ${ }^{15,38}$ contain low levels of linoleic, linolenic and arachidonic acids and increased accumulation of 5,8,11-eicosatrienoic acid [20:3 (n-9)] and oleic acid [18:1 (n-9)]. The (n-9)-type of fatty acid, eicosatrienoic acid and oleic acid, are not substrates for prostaglandin synthesis ${ }^{35}$. Investigation of essential fatty acid deficiency in animals, first described by BURR and BURR ${ }^{8}$ and by HoLMAN ${ }^{19}$, has so far been restricted mostly to nutritional studies. Recent reports have, however, indicated the usefulness of EFA deficiency in the study of the roles of prostaglandins in pathophysiology. Prostaglandin synthesis has been reported to be suppressed in experimentally induced essential fatty acid deficiency in rats ${ }^{28}$. BONTA et al. ${ }^{4}$ reported suppression of prostaglandin-mediated carrageenin-induced hind paw inflammation in EFA-deficient rats due to shortage of prostaglandin precursors. EFA deficiency in rats has been used to study the

Key-words: Essential fatty acid deficient rats; Insulin and glucagon secretion; Prostaglandins. Received: September 1, 1980.

Acta diabet. lat. 18, 147, 1981. 
roles of prostaglandins in acute ${ }^{5,22}$ and chronic inflammatory processes ${ }^{6,11,27}$ and to discriminate prostaglandin and non-prostaglandin-mediated components of inflammation ${ }^{4}$.

A variety of prostaglandins affect various endocrine secretory functions including the endocrine control of sugar homeostasis ${ }^{39}$. FSH and LH secretion from rat pituitary is enhanced by $\mathrm{PGE}_{2}$ and $\mathrm{PGF}_{2 \alpha}{ }^{17,25}$. The stimulation of gonadotropin release by prostaglandins is explained to be exerted directly on the hypothalamo-pituitary unit as well as mediated by actions on the gonads ${ }^{9,16}$. Stimulation of thyroxine release by thyrotropin may be mediated by prostaglandins ${ }^{26}$. The possible role of prostaglandins in the regulation of pancreatic endocrine secretion and in the etiology of diabetes mellitus has been investigated. Prostaglandins were first reported to affect insulin secretion in $1968^{7}$. Although evidence implicating prostaglandins as insulin secretagogues is conflicting, the stimulatory effects of administered prostaglandins on glucagon secretion appear to be consistent. In the isolated perfused rat pancreas, reports ${ }^{30,31,32}$ show that in the presence of glucose $(5.6 \mathrm{mmol} / 1), \mathrm{PGE}_{1} \mathrm{PGE}_{2}$ and $\mathrm{PGF}_{2 \alpha}$ evoked biphasic release of glucagon and insulin. Recently, we have reported that prostaglandin endoperoxide, $\mathrm{PGH}_{2}$, is a secretagogue for glucagon and insulin (equipotent with the classical prostaglandins, $\mathrm{PGE}$ and $\mathrm{PGF}_{2 a}$ ) and also that thromboxane $\left(\mathrm{TXA}_{2}\right.$ and $\left.\mathrm{TXB}_{2}\right)$ and prostacyclin $\left(\mathrm{PGI}_{2}\right)$, were not effective secretagogues, whereas $\mathrm{PGD}_{2}$ is a more potent stimulant of glucagon than insulin secretion ${ }^{2}$. A comprehensive assessment of the current reported effects of prostaglandins on insulin and glucagon secretion is available in our recent publication ${ }^{2}$ and that of ROBERTSON ${ }^{33}$. In the present study, isolated pancreata from rats deficient in essential fatty acids were perfused to ascertain the role of prostaglandin precursors in the endocrine pancreas secretory response to insulin and glucagon secretagogues.

\section{MATERIALS AND METHODS}

Weanling albino rats of the Sprague-Dawley strain were maintained for 16 weeks on a diet deficient in essential fatty acids (Nutritional Biochemical) and housed under controlled conditions of humidity, light and temperature. Food and water were available ad libitum. Control rats received standard laboratory chow. The principal apparent manifestations of essential fatty acid deficiency were diminished growth rate and scaly dermatitis, mainly on the feet and tail. The animals were anesthetized with sodium pentobarbital $(50 \mathrm{mg} / \mathrm{kg})$ injected i.p. and the pancreas with its intact vasculature was removed and transferred to an extracorporeal perfusion apparatus as described previously ${ }^{31}$. The perfusion solution contained $120 \mathrm{mmol} / 1$ $\mathrm{NaCl}, 4.7 \mathrm{mmol} / 1 \mathrm{KCl}, 0.8 \mathrm{mmol} / 1 \mathrm{MgSO}_{4}, 2.4 \mathrm{mmol} / 1 \mathrm{CaCl}_{2}, 1.2 \mathrm{mmol} / 1 \mathrm{KH}_{2} \mathrm{PO}_{4}$, $25 \mathrm{mmol} / 1 \mathrm{NaHCO}_{3}, 5.6 \mathrm{mmol} / 1 \mathrm{D}$-glucose, $56 \mu \mathrm{mol} / 1$ dextran and $30 \mu \mathrm{mol} / 1$ bovine serum albumin. The perfusion flow rate was kept constant at $2.5 \mathrm{ml} / \mathrm{min}$. Perfusion pressure was monitored continuously using a pressure transducer, an amplifier, and a strip-chart recorder. After a 30-min equilibration period, the experimental protocol was commenced.

The perfusion system employs four independent perfusion channels connecting four corresponding reservoirs which merged into a manifold to which the aortic cannula was connected. With the use of four independent perfusion channels, individual test agents contained in each reservoir can be diverted to perfuse the pancreas via a common aortic cannula. L-arginine monohydrochloride (ICN) (10 
mmol/l), L-leucine (Sigma) $(10 \mathrm{mmol} / \mathrm{l})$ or bovine growth hormone (NIH) (100 $\mu \mathrm{mol} / \mathrm{l})$ were dissolved in the basic perfusion medium and added shortly before the experiments to the appropriate reservoir and equilibrated at $37^{\circ} \mathrm{C}$ with a mixture of $95 \%$ oxygen and $5 \%$ carbon dioxide. Depending on the experimental protocol, rat pancreata were perfused with each secretagogue (with the exception of glucose) for $1 \mathrm{~min}$, separated by a 15 -min period, during which the pancreata were perfused with basic buffer solution only. Perfusion media contained 5.6 $\mathrm{mmol} / 1$ glucose at all times. A solution containing $16.7 \mathrm{mmol} / 1 \mathrm{D}$-glucose was perfused for $30 \mathrm{~min}$. The pancreatic portal venous effluent was collected in 1-min fractions; the samples were chilled immediately, aliquoted for submission to radioimmunoassays, and stored at $-20^{\circ} \mathrm{C}$ until the time of assay.

Radioimmunoassays for glucagon and insulin were performed using the 'doubleantibody' method described previously ${ }^{29}$. Beef-pork glucagon and rat insulin were used as standards in the respective assays. The 5 -min total response areas (where applicable) were computed as described previously 29,34 . The amounts of hormone secreted in this time period were derived by multiplying the concentration of each 1 -min sample by the flow rate and summing these values for the 5-min interval. The statistical significance of differences between observed values was determined by two-tailed Student's $t$-test. Values are given as mean \pm SEM.

One-hundred-milligram pieces of tissue, pancreas, liver, heart, lung, kidney and skeletal muscle excised from EFA deficient rats and control rats (pancreas only) were homogenized for $20 \mathrm{sec}$ in chloroform/methanol $(2: 1, \mathrm{v} / \mathrm{v})$ and acidified with formic acid. The homogenate was heated to $70^{\circ} \mathrm{C}$ for $10 \mathrm{~min}$, cooled and centrifuged. The organic phase was separated and extracted with formic acid according to the procedure of FoLCH et al. ${ }^{13}$ and then methylated with $8 \%$ concentrated sulfuric acid in methanol. The methyl esters were analyzed by means of gas-liquid chromatography (Varian 3700) on a 10\% diethylene glycol succinate (DEGS-PS) glass column at $185^{\circ} \mathrm{C}$ using a flame-ignition detector (FID). Fatty acid esters were identified by use of pure standards. The peak areas were quantified by an automatic digital integrator (Varian). The fatty acid values are expressed as mol \% (mean \pm SEM).

\section{RESULTS}

Fatty acid levels of EFA deficient rats - Tab. 1 summarizes data on fatty acid content of pancreata obtained from control rats and EFA deficient rats. These rats were similar to those used in isolated pancreas perfusion to assess hormone release. It can be clearly seen that the level of oleate $(18: 1, \mathrm{n}-9)$ was significantly lower in the control rats than in the EFA-deficient rats. The increased level of oleate which is a non-essential fatty acid, is probably due to preferential accumulation during essential fatty acid deficiency. Eicosatrienoic acid (20:3, n-9) which like oleate is a non-prostaglandin precursor, was present in trace amounts in control rats, but was significantly elevated in EFA-deficient rats. On the contrary, arachidonic acid $(20: 4, \mathrm{n}-6)$ and linoleic acid $(18: 2, \mathrm{n}-6)$ which can serve as substrates for prostaglandin synthesis 3,36 were higher in control rats $(15 \pm 2$ and $19 \pm 3$, respectively) but were present only in trace amounts in EFA-deficient rats $(1.6 \pm 0.5$ and $1.0 \pm 0.4$, respectively). Whereas the triene:tetraene $(20: 3, n-9 / 20: 4, n-6)$ ratio was very low (0.027) as would be expected, this ratio was 8.8 in EFA-deficient 


\section{INSULIN AND GLUCAGON IN EFA DEFICIENT RATS}

rats, which represents approximately $15,000 \%$ increase over the control (tab. 1). The high triene:tetraene ratio is indicative of severe EFA deficiency and is comparable to ratios previously reported by other investigators $11,15,19,27$.

In tab. 2 are shown data on fatty acid content of various organs obtained from EFA-deficient rats prior to perfusion of pancreata to ascertain hormone

\begin{tabular}{c|c|c}
\hline type of fatty acid & control rats $(\mathrm{n}=4)$ & EFA-deficient rats $(\mathrm{n}=3)$ \\
\hline $16: 0$ & $28 \pm 3$ & $28 \pm 4$ \\
$16: 1$ & $2 \pm 1$ & $8 \pm 0.5$ \\
$18: 0$ & $14 \pm 0.4$ & $7.2 \pm 0.9$ \\
$18: 1(\mathrm{n}-9)$ & $12 \pm 0.8$ & $38 \pm 2$ \\
$18: 2(\mathrm{n}-6)$ & $19 \pm 3$ & $1 \pm 0.4$ \\
$20: 3(\mathrm{n}-9)$ & $0.4 \pm 0.3$ & $14 \pm 1$ \\
$20: 4(\mathrm{n}-6)$ & $15 \pm 2$ & $1.6 \pm 0.5$ \\
\hline total fatty acids & $69.0 \pm 2$ & $74.0 \pm 1$ \\
$($ nmol/mg) & & $8.8 \pm 2$ \\
\hline
\end{tabular}

* 20:3, $\mathrm{n}-9 / 20: 4, \mathrm{n}-6$ ratio

Tab. 1 - Mean mole percent ( \pm SEM) fatty acid content of control and EFA-deficient rat pancreata. Values were computed as percent of total nmol fatty acid per mg tissue for $(n)$ observations calculated with the method of FoLCH et al. ${ }^{13}$.

\begin{tabular}{|c|c|c|c|c|c|c|}
\hline $\begin{array}{l}\text { type of } \\
\text { fatty acid }\end{array}$ & $\begin{array}{c}\text { liver } \\
(n=4)\end{array}$ & $\begin{array}{c}\text { skeletal } \\
\text { muscle } \\
(\mathrm{n}=3)\end{array}$ & $\begin{array}{c}\text { adipose } \\
\text { tissue } \\
(\mathrm{n}=2)\end{array}$ & $\begin{array}{c}\text { heart } \\
(n=4)\end{array}$ & $\begin{array}{c}\text { lung } \\
(n=2)\end{array}$ & $\begin{array}{l}\text { kidney } \\
(n=2)\end{array}$ \\
\hline $16: 0$ & $24 \pm 3$ & $26 \pm 4$ & $24 \pm 1$ & $12 \pm 1$ & $40 \pm 3$ & $28 \pm 1$ \\
\hline $16: 1$ & $6 \pm 1$ & $10 \pm 2$ & $19 \pm 1$ & $3 \pm 1$ & $9 \pm 1$ & $5 \pm 0.2$ \\
\hline $18: 0$ & $17.3 \pm 2$ & $7.3 \pm 2$ & $2 \pm 0.1$ & $23.2 \pm 3$ & $12 \pm 1$ & $21 \pm 0.5$ \\
\hline $18: 1(n-9)$ & $31.5 \pm 1$ & $42 \pm 2$ & $52 \pm 0.4$ & $27 \pm 2$ & $23 \pm 2$ & $25.3 \pm 0.2$ \\
\hline $18: 2(n-6)$ & $0.9 \pm 0.2$ & $1.1 \pm 0.2$ & - & $1.2 \pm 0.1$ & $0.2 \pm 0$ & $0.7 \pm 0$ \\
\hline $20: 3(n-9)$ & $11.2 \pm 2$ & $13.3 \pm 3$ & $9 \pm 0.1$ & $24.1 \pm 3$ & $6 \pm 0.2$ & $9.2 \pm 0.4$ \\
\hline $20: 4(n-6)$ & $3.2 \pm 0.5$ & $1.4 \pm 0.6$ & - & $3.5 \pm 0.6$ & $0.8 \pm 0.1$ & $3.5 \pm 0.1$ \\
\hline $\begin{array}{l}\text { total } \\
\text { fatty acids } \\
\text { (nmol/mg) }\end{array}$ & $104 \pm 5$ & $84 \pm 13$ & $309 \pm 31$ & $57 \pm 1$ & $49 \pm 1$ & $47 \pm 2$ \\
\hline $\begin{array}{l}\text { triene/tetraene } \\
\text { ratio * }\end{array}$ & $3.5 \pm 2$ & $9.5 \pm 5$ & - & $6.9 \pm 5$ & $7.5 \pm 1$ & $2.63 \pm 4$ \\
\hline
\end{tabular}

* 20:3, n-9/20:4, n-6 ratio

Tab. 2 - Mean mole percent ( \pm SEM) fatty acid content of various organs obtained from EFA deficient rats prior to perfusion of pancreata to ascertain hormone release. Values were computed as percent of total nmole fatty acid per $\mathrm{mg}$ tissue for $(\mathrm{n})$ observations calculated with the method of FoLCH et al. ${ }^{13}$. 


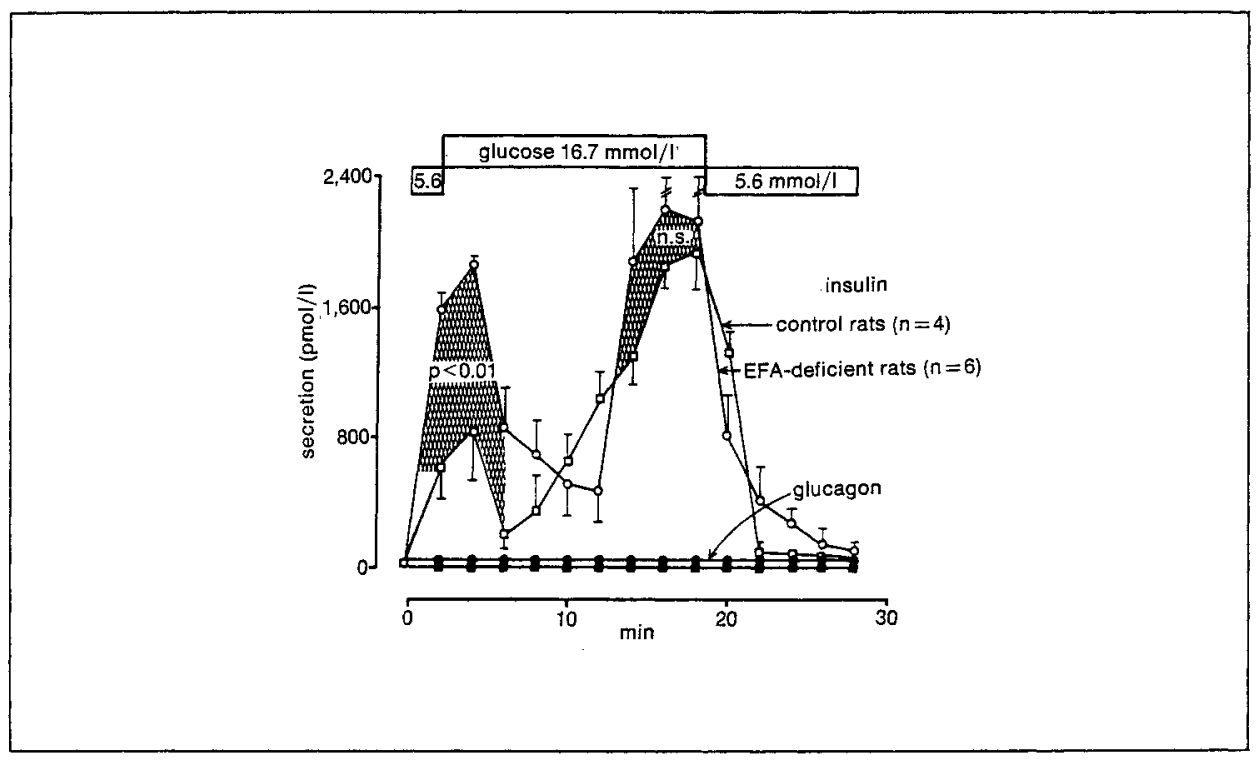

Fig. 1 - Each point represents mean \pm SEM of either insulin secretion in EFA-deficient rats $(\square-a, \mathrm{n}=6)$ and control rats $(0-0, \mathrm{n}=4)$ or glucagon secretion $(\square-\cdots, \mathrm{n}=6)$ in EFA-deficient rats and $(\bullet \bullet, n=4)$ in control rats.

release. As in tab. 1, the levels of non-prostaglandin precursor fatty acids such as $18: 1, \mathrm{n}-9$ and 20:3, n-9 were high in all the organs measured. These values were comparable to those reported in the literature for severely EFA-deficient animals ${ }^{15,19}$. In contrast, the prostaglandin-precursor fatty acids $(20: 4, \mathrm{n}-6$ and $18: 2, \mathrm{n}-6)$ were present in trace amounts. The triene:tetraene $(20: 3, \mathrm{n}-9 / 20: 4, \mathrm{n}-6)$ ratios were as follows: liver $3.5 \pm 2$; skeletal muscle $9.5 \pm 5$; heart $6.9 \pm 5$; lung $7.5 \pm 1$ and kidney $2.6 \pm 4$. These high ratios are evidence of severe essential fatty acid deficiency and suppressed endogenous prostaglandin synthesis ${ }^{10,13,27}$.

Glucose-stimulated glucagon and insulin secretion - Fig. 1 illustrates the dynamics of insulin and glucagon secretion in response to an increase in the concentration of glucose from 5.6 to $16.7 \mathrm{mmol} / 1$. The pattern of the insulin secretory response to glucose $16.7 \mathrm{mmol} / 1$ perfused for $30 \mathrm{~min}$ was biphasic both in control and EFAdeficient rats. The glucose stimulated acute secretion (phase I) was significantly greater $(\mathrm{p}<0.01)$ in magnitude and amplitude in EFA-deficient (open circles) than in the control rats (open squares). There was no significant difference in the second phase of glucose-stimulated insulin secretion between the two groups. There was, however, a slow return to nadir following phase-1 secretion in the EFA-deficient rats. This probably was a normal elution decay in view of the greater amounts of phase-1 insulin in EFA-deficient rats compared to control rats. Glucagon secretion in the control and EFA-deficient rats was inhibited as would be expected by high glucose concentration.

Glucagon and insulin secretion in response to common secretagogues - Tab. 3 summarizes data on glucagon and insulin secretory response to 1-min perfusions of pancreata isolated from EFA-deficient and control rats with L-arginine (10 
$\mathrm{mmol} / \mathrm{l})$, bovine growth hormone $(100 \mu \mathrm{mol} / \mathrm{l})$ or L-leucine $(10 \mathrm{mmol} / 1)$. Glucagon secretion in response to arginine was not significantly different in control and EFAdeficient rats $(1,647 \pm 591$ vs $1,223 \pm 233$, respectively). However, the magnitude of arginine-stimulated insulin release was significantly higher in EFA-deficient than in control rats $(5,309 \pm 863$ vs $2,665 \pm 357)$. Growth hormone-induced secretion was variable in the two groups. Whereas bGH-induced glucagon release was much higher in the control rats, insulin secretion was significantly higher in EFA-deficient rats. Glucagon and insulin secretion in response to L-leucine was minimal but significantly higher than basal secretion ( $428 \pm 42$ vs $49 \pm 11$, glucagon; 233 \pm 88 vs $60 \pm 18$, insulin). There was no corresponding observation of leucine effect in the control rats.

\section{DISCUSSION}

Prostaglandins and related arachidonic acid metabolites are ubiquitous in animal tissues and regulate a variety of biological processes, including hormone secretion. Administered prostaglandins and inhibitors of prostaglandin synthesis modify the secretion of glucagon and insulin, often with conflicting results, as previously reviewed ${ }^{2,33}$. The purpose of the present investigation was to determine the effect of suppressed or deprived prostaglandin synthesis upon insulin and glucagon secretion in response to common secretagogues. Data summarized in tabs 1 and 2 convincingly indicate severe EFA deficiency in our animal model. In the pancreas of the EFA. deficient rats, the ratio of trienoic to tetraenoic fatty acids was 8.8. A condition of EFA deficiency in rats with triene/tetraene ratios of 4 or greater has been reported to result in progressive suppression of prostaglandin synthesis ${ }^{28}$. Prostaglandin production by platelets obtained from EFA deficient rats was suppressed relative to the degree of EFA-deficiency ${ }^{28}$. CRAWFORD et al. ${ }^{13}$ have shown that $\mathrm{PGE}_{1}, \mathrm{PGE}_{2}$ and $\mathrm{PGE}_{2 \alpha}$ content of tissues from EFA-deficient rabbits was significantly lower than in normal rabbits. In these rabbits, there was a corresponding decrease in linoleic and dihomo- $\gamma$-linolenic acids, fatty acids which are substrates for prostaglandin synthesis. Our fatty acid data presented in tabs 1 and 2 are consistent with those previously reported ${ }^{13}$.

\begin{tabular}{l|r|r|r|r}
\hline \multirow{2}{*}{ agents } & \multicolumn{2}{|c|}{ glucagon (fmol/5 min) } & \multicolumn{2}{c}{ insulin (fmol/5 min) } \\
\cline { 2 - 5 } & \multicolumn{1}{|c|}{ control rats } & EFA-deficient rats & \multicolumn{1}{c}{ control rats } & EFA-deficient rats \\
\hline basal & $42 \pm 8 \quad(\mathrm{n}=8)$ & $49 \pm 11 \quad(\mathrm{n}=6)$ & $28 \pm 15(\mathrm{n}=8)$ & $60 \pm 18(\mathrm{n}=6)$ \\
$\begin{array}{l}\text { arginine } \\
(10 \mathrm{mM})\end{array}$ & $1647 \pm 591(\mathrm{n}=4)$ & $1223 \pm 233(\mathrm{n}=8)$ & $2665 \pm 357(\mathrm{n}=4)$ & $5309 \pm 863(\mathrm{n}=8)$ \\
bGH \\
$\begin{array}{l}(100 \mathrm{mmol} / \mathrm{l}) \\
\text { L-leucine } \\
(10 \mathrm{mM})\end{array}$
\end{tabular}

Tab. 3 - Values represent 5 -min cumulative portal effluent glucagon ( $\mathrm{fmol} / 5 \mathrm{~min}$ ) and insulin (fmol/5 $\mathrm{min}$ ) secretion following 1 -min perfusion with agents indicated. The amount of hormone released in the subsequent $5 \mathrm{~min}$ is given as the mean $\pm S E M$ for the number of experiments indicated in parentheses. 
The high triene/tetraene ratio (8.8) in EFA-deficient rats compared to 0.027 in the controls (tab. 1) indicates that there was little or no arachidonate in the EFA-deficient rats. In corollary, there was no substrate for prostaglandin synthesis, and hence, no potential for any significant synthesis of prostaglandins.

Our results on hormone release illustrated in fig. 1 demonstrate a slightly augmented secretory function of the islets of Langerhans in EFA deficiency. However, the similar pattern and dynamics of glucagon secretion in both the control and EFA-deficient rats suggest a non-mandatory regulatory role of prostaglandins in endocrine pancreas secretion. The enhanced magnitude of phase-1 (acute phase) insulin release induced by glucose in EFA-deficient rats as compared to controls, probably indicates a possible inhibitory effect of prostaglandins ${ }^{33}$. As shown in tab. 3, glucagon and insulin secretory response to secretagogues such as bGH and leucine which induce hormone release by mechanism(s) possibly different and unrelated ${ }^{34}$ was unaltered by EFA deficiency. There was significantly enhanced argininestimulated insulin secretion in the EFA-deficient rats.

The present observations by no means pose logical contradiction to our previously reported stimulation by exogenously administered prostaglandins in isolated perfused pancreas $2,29,30,31,32$. However, the mechanism(s) by which administered prostaglandins elicit hormone release could be different and unrelated to the actions of the endogenous prostaglandins. Prostaglandins are a very potent and active class of lipids and could probably modify hormone release in in vitro conditions such as the perfused pancreas without any obligatory regulation of endocrine pancreas secretion.

The mechanism by which administered prostaglandins modulate the secretory activity of endocrine glands is often attributed to interaction of their specific membrane receptors with adenylate cyclase ${ }^{10,20}$, since prostaglandins generally elevate the level of cyclic AMP in tissues and affect metabolic functions regulated by cyclic AMP. The stimulant effect of prostaglandins on endocrine secretion also seems to involve alteration in intracellular calcium concentrations ${ }^{10,20}$, although HERTELENDY et al. ${ }^{21}$ reported that the prostaglandins do not act as ionophores. The pharmacological effects of administered prostaglandins could involve direct action on the cell membrane. Mishima and Kuriyama ${ }^{18}$ reported depolarization of guinea pig stomach longitudinal muscle membrane by $P G E_{1}, P G E_{2}$, or $\mathrm{PGE}_{2 \alpha}$, suggesting that these prostaglandins may increase calcium influx by stimulating electrical activity of the membrane. Changes in membrane depolarization with the associated calcium influx in response to pancreatic endocrine hormone secretagogues is a well-established phenomenon.

Several reports show that inhibitors of prostaglandin synthesis augment or stimulate secretion of insulin ${ }^{12,14,24}$. These observations indicate that endogenous prostaglandins may have an inhibitory role on insulin secretion. Our data in fig." 1 : demonstrating an enhanced phase-1 glucose-stimulated insulin secretion in EFAdeficient rat are in agreement with the concept of an inhibitory role of endogenous prostaglandins. MACADAMs et al. ${ }^{23}$ observed augmentation of stimulated insulin secretion from isolated perfused pancreas when the donor rats had been pretreated with nictindole (L8027, a combined inhibitor of cyclooxygenase and thromboxane synthase) and indomethacin had been added to the perfusion solutions ${ }^{37}$.

We have provided evidence that the secretory function of the endocrine pancreas is operational in EFA deficiency, a condition in which there is deficiency of sub- 
strates for prostaglandin synthesis. Our studies may exemplify the lack of an obligatory role of prostaglandins in insulin and glucagon secretion. The use of EFA-deficient animals as a model for the study of the role of prostaglandins in endocrine pancreas and other endocrine gland secretions could resolve the conflicting findings concernitg the effects of prostaglandins.

\section{ACKNOWLEDGEMENTS}

The authors are indebted to Dr. Sumer Pek of the Department of Internal Medicine (Division of Endocrinology and Metabolism and The Metabolism Research Unit), The University of Michigan, for providing research facilities, support and for critical editorial assistance. These studies were supported in part by United States Public Health Service grants AM-21192, AM-02244, and AM-20572 (Michigan Diabetes Research and Training Center) from the National Institute of Arthritis, Metabolism, and Digestive Diseases. The radioimmunoassays for glucagon and insulin were performed in the Ligand Assay Core Laboratory of the Michigan Diabetes Research and Training Center.

\section{SUMMARY}

Insulin and glucagon secretion in response to common secretagogues were ascertained in the perfused pancreas isolated from essential fatty acid deficient rats. The pattern of insulin secretory response to glucose $(16.7 \mathrm{mmol} / \mathrm{l})$ by isolated rat pancreas perfused for $30 \mathrm{~min}$ was biphasic in EFA-deficient and control rat pancreas. The amplitude of glucose-stimulated acute secretion (phase I) was significantly greater $(\mathrm{p}<0.01)$ in magnitude and amplitude in EFA-deficient rats than in the control rats. There was no significant difference in the second phase of glucosestimulated insulin secretion in the two groups. Glucagon secretion in EFA-deficient and control rats was inhibited by glucose $(16.7 \mathrm{mmol} / 1)$. Glucagon secretion induced by L-arginine (10 mmol/1) was not significantly different in EFA-deficient and in control rat pancreata $(p>0.05)$. However, arginine (10 mmol/1)-stimulated insulin release was significantly higher in EFA-deficient than in control rats. Growth hormone $(100 \mu \mathrm{mol} / \mathrm{l})$-induced glucagon and insulin secretion was variable in the two groups but significantly higher than basal secretion. The level of L-leucine (10 mmol/1)-stimulated glucagon and insulin secretion in EFA-deficient rats was minimal but significant. Our results show that isolated pancreata of rats devoid of precursors for endogenous prostaglandin synthesis secreted insulin and glucagon in response to common secretagogues. On the basis of our data, it is concluded that endogenous prostaglandins are probably not obligatory for normal secretory functions of islets of Langerhans.

\section{REFERENCES}

1) Aes-Jorgensen E.: Essential fatty acids - Physiol. Rev. 41, 1, 1961.

2) Akpan J.O., Hurley M. C., Pek S., Lands W. E. M.: The effects of prostaglandins on secretion of glucagon and insulin by perfused rat pancreas - Canad. J. Biochem. 57, 540, 1979.

3) Bergström S., Danielson H., Samuelsson B.: The enzymatic formation of prostaglandin $\mathrm{E}_{2}$ from arachidonic acid, prostaglandins and related factor 32 - Biochim. biophys. Acta (Amst.) 90, 207, 1964.

4) Bonta I. L., Bult H., Ven L.L.M. v.d., Noordhoek J.: Essential fatty acid deficiency: a condition to discriminate prostaglandin and non-prostaglandin mediated components of inflammation - Agents a. Actions 6, 154, 1976.

5) Bonta I.L., Bult H., Vincent J.E., ZiJlstra F. J.: Acute anti-inflammatory effects of aspirin and dexamethasone in rats deprived of endogenous prostaglandin precursors - J. Pharm. Pharmacol. 29, 1, 1977

6) Bonta I.L., Parnham M. J., Adolfs M. J.P.: Reduced exudation and increased tissue proliferation during chronic inflammation in rats deprived of endogenous prostaglandin precursors - Prostaglandins 14, 295, 1977.

7) Bressler R., Veirgas-Condon M., Lebovitz H. E.: Tranylcyptomine: a potent insulin secretagogue and hypoglycemic agent - Diabetes 17, 617, 1968.

8) BurR G. O., BurR M. M.: A new deficiency disease produced by rigid exclusion of fat from the diet - J. biol. Chem. 82, 345, 1929. 
9) Burton N., Carlike S., Jubiz W.: Prostaglandin $F_{2 a}\left(P_{2} F_{2 a}\right)$ - Prostaglandins 10, 667, 1975.

10) Craffford M. A., Denton J.P., Hassam A. G., Lynn J., Marples P., Stevens P., Willis A. L.: Levels of prostaglandins and their precursors in EFA deficient rabbits - a new concept of prostaglandin biosynthesis - Brit. J. Pharmacol. 63, 363, 1978.

11) Denko C. W.: Modification of adjuvant inflammation in rat deficient in essential fatty acid . Agents a. Actions 6, 636, 1976.

12) Dodi G., SAntoro M.G., JAFFe B.M.: Effect of a synthetic analogue on exocrine and endocrine pancreatic function in the rat - Surgety 83, 206, 1978.

13) Folch J., Lees M., Sloane-Stanley H.: A simple method for the isolation and purification of total lipids from animal tissues - J. biol. Chem. 226, 497, 1957.

14) Givgliano D., Torella R.: Prostaglandin $E_{1}$ inhibits glucose-induced insulin secretion in man - Prostaglandins Med. 1, 165, 1978.

15) Hassam A.G., Crawford M. A.: The effect of dihomo- $\gamma$-linolenic acid (20:3, n-6) on the composition of phospholipid fatty acids in the liver of rats deficient in essential fatty acids. Brit. J. Nutr. 40, 155, 1978.

16) Haye B., Champion S., Jacquemin C.: Control by TSH of a phospholipase $A_{2}$ activity, a limiting factor in the biosynthesis of prostaglandins in the thyroid - FEBS Letters 30,253, 1973.

17) HEDGE G. A.: Roles for the prostaglandins in the regulation of anterior pituitary secretion Life Sci. 20, 17, 1977.

18) Hertelendy F., Todd H., Narconis R. J. Jr.: Studies on growth hormone secretion. IX. Prostaglandins do not act like ionophores - Prostaglandins 15, 575, 1978.

19) Holman R. T.: Biological activities of and requirement for polyunsaturated fatty acids - In: Holman R. T. (Ed.): Progress in the chemistry of fats and other lipids, vol. 9. Pergamon Press, Oxford, 1970; p. 607.

20) Johnson D.G., Thompson W. J., Williams R.H.: Regulation of adenylyl cyclase from isolated pancreatic islets by prostaglandins and guanosine t'triphosphate - Biochemistry $13,1920,1974$.

21) Lefbowitz R. J., Mullikin D., Wood C. L., Gore T.B., Mukhejee C.: Regulation of prostaglandin receptors by prostaglandins and guanine nucleotides in frog erythrocytes J. biol. Chem. 252, 5295, 1977.

22) Lowe N. J., Stoughton R. B.: Essential fatty acid deficient hairless mouse: a model of chronic epidermal hyperproliferation - Brit. J. Derm. 96, 155, 1977.

23) Macadams M. R., Pek S.: Inhibitors of prostaglandin synthetic pathway enhanced in vitro secretion of glucagon and insulin - 61th Annual Meeting of the Endocrine Society, Anaheim/ Calif. 1979 ; p. 169.

24) Mrshima K., Kuriyama H.: Effects of prostaglandins on electrical and mechanical activities of the guinea pig stomach - Jap. J. Physiol. 26, 537, 1976.

25) Nakano J.: General pharmacology of prostaglandins - In: Cuthbert M.F. (Ed.): Prostaglandins. Heinemann Medical Books, London, 1973; p. 23.

26) OJEda S.R., Jameson H.E., McCanN S. M.: Prostaglandin $E_{2}$ (PGE ( $_{\text {-induced growth }}$ hormone $(\mathrm{GH})$ release: effect of intrahypothalamic and intrapituitary implants - Prostaglandins $13,943,1977$.

27) Parnham M. J., Shoshan S., Bonta I. L., Neiman-Wollner S.: Increased collagen metabolism in granulomata induced in rats deficient in endogenous prostaglandin precursors - Prostaglandins 14, 709, 1977.

28) Parham M. J., Vincent J.E., Zijlstra F. J., Bonta I. L.: The use of essential fatty acid deficient rats to study pathophysiological roles of prostaglandins. Comparison of prostaglandin production with some parameters of deficiency - Lipids 14, 407, 1979.

29) Pex S.: Glucagon and insulin - In: RothField B. (Ed.): Nuclear medicine: endocrinology. B. Lippincott, Philadelphia, 1978; p. 122.

30) PEK S., TAI T.-Y., Elster A.: Stimulatory effects of prostaglandins E-1, E-2 and F-2-alpha on glucagon and insulin release in vitro - Diabetes 27, 801, 1978.

31) Pek S., Tat T.-Y., Elster A., Fajans S.S.: Augmentation by prostaglandins of glucagon (IRG) and insulin (IRI) release from isolated rat pancreas - Clin. Res. 22, 619A, 1974.

32) Pek S., TaI T.-Y., Elster A., FaJANS S.S.: Stimulation by prostaglandin $E_{2}$ of glucagon and insulin release from isolated rat pancreas - Prostaglandins 10, 493, 1975. 
33) Robertson P.R.: PGs and the pathogenesis of diabetes - Prostaglandins a. Therapeutics 4, 1, 1978.

34) TAI T.-Y.: Direct stimulation by growth hormone of glucagon and insulin release from isolated rat pancreas - Endocrinology 99, 669, 1976.

35) VAN DoRp D.A.: Essential fatty acids and prostaglandins - In: 24th Int. Congr. of Pure and Applied Chemistry. Butterworths, London, 1974; vol. 2, p. 117.

36) Van Dorp D. A., Beerthuis R. K., Nuysteren D. H., Vonkeman H.: The biosynthesis of prostaglandins - Biochim. biophys. Acta (Amst.) 90, 204, 1964.

37) WIDSTRÖM A.: Influence of indomethacin on glucose-induced insulin response in normal man; role of prostaglandins in the rapid insulin release? - Hormone metab. Res. 9, 172, 1977.

38) Zівон V.A., HsIA S. L.: Effects of prostaglandin $E_{2}$ on rat skin: inhibition of sterolester biosynthesis and cleaning of scaly lesions in essential fatty acid deficiency - J. Lipid Res. $13,458,1972$

39) Ziboh V.A., VANDERHoEk J.Y., LANDS W.E. M.: Inhibition of sheep vesicular gland oxygenase by unsaturated fatty acids from skin of essential fatty acid deficient rats - Prostaglandins 5, 233, 1974.

Requests for reprints sbould be addressed to:

\author{
Jones O. AKPan \\ Department of Clinical Pbarmacology \\ University of Ilorin \\ Ilorin, Kwara State - Nigeria
}

